\title{
Learning L2 Vocabulary with American TV Drama From the Learner's Perspective
}

\author{
Yu-Chia Wang ${ }^{1}$ \\ ${ }^{1}$ Department of English, National Taiwan Normal University, Taiwan \\ Correspondence: Yu-Chia Wang,162, Heping East Road Section 1, Taipei, Taiwan. E-mail: ycw233@gmail.com
}

Received: April 5, 2012 Accepted: May 16, 2012 Online Published: July 11, 2012

doi:10.5539/elt.v5n8p217 URL: http://dx.doi.org/10.5539/elt.v5n8p217

\begin{abstract}
Following the trend of computer assisted language learning (CALL), in Taiwan, most language classes now have equivalent media support for language teachers and learners. Implementing videos into classroom activities is one of the choices. The current study explores the process of implementing American TV drama in L2 vocabulary learning from learners' perspectives. Twenty-eight Taiwanese EFL adult learners participate in the study. Authentic video clips from three different American dramas- "How I met your mother", "The King of Queens", and "Reba" are adopted. After three sessions of class activities including clip watching, class discussion, word listing, etc., students complete a 4-likert scale questionnaire and are individually interviewed by the researcher to give their opinions. The results reveal positive comments on the facilitative role of TV drama in learning new vocabulary as previous studies suggested, but learners' comments point out some crucial factors while learning L2 vocabulary with TV drama. First of all, the interest level and the familiarity of the content is an important factor. In addition, the images, subtitles and repetition help participants to "remember" the target words. Other factors such as the authenticity of the language, the contextual meaning of the words, and the dramatic performances all contribute to the learning of the L2 vocabulary. In the end of the study, working memory system, the context, acquisition-learning hypothesis (Krashen, 1981), and noticing hypothesis (Schmidt, 1990) are further discussed.
\end{abstract}

Keywords: L2 vocabulary learning, American TV drama, Taiwan

\section{Introduction}

More and more often, teachers are encouraged to implement multimedia tools such as audios or videos in language classrooms because they seem to be more convenient, entertaining, and most of the time very handy. From previous studies, a number of researchers have claimed the effectiveness of combining audio and visual aids in language classrooms. They argued that visual input combining with other technology tools stimulates deeper comprehension of the texts and enhances the interaction between the target language and learners' mind which in term, allow learners to predict the target language more easily and to recall more fully (Neuman et al., 1990; Stevens, 1989; Svensson \& Borgarskila, 1985; Underwood, 1990). For example, Oxford \& Crookall (1990) found that the combination of pictorial and audio aids provided learners with multiple opportunities to access more parts of the brain and to process information more effectively. In addition to its effects on increasing learner's overall language ability, the strength of using multimedia tools in enhancing vocabulary learning has also been studied and reported. For example, Canning-Wilson (2000) found that images contextualized in video can help to reinforce lexical learning which provided the learners to see immediate meaning in terms of vocabulary recognition. Moreover, Hoogeveen (1995) proposed other values of using multimedia tools in language classrooms where learners might respond to the information with more personal feelings instead of just receiving it. Besides, the multimedia tools turn learning into a more fun and happier process.

However, there has been a neglect of studies on "how" do learners perceive their learning with multimedia tools and "how" they actually learn L2 words through the process. In other words, the knowledge of the process of learning L2 words through multimedia tools such as videos still remains unexplored. Can learners be motivated by the videos like the statistics told us? Are learners aware of themselves learning L2 words while experiencing the process of watching videos? What are their reactions toward the learning process? In what ways is watching videos better or worse than reading written texts in terms of learning L2 vocabulary? Combining questions mentioned above, the purpose of this study aims to explore the phenomenon of an EFL classroom where 
authentic video clips (American TV drama) are used to help students to learn target vocabulary, including learner's attitudes and opinions.

\section{Literature Review}

\subsection{Media-based Teaching and Learning}

In a traditional language classroom, written text (textbook) is always the main material used by teachers and sometimes it is also the only exposure provided to learners. However, thanks to the invention of computers and because of its strong impact on our daily life, teachers can have more choices nowadays to present teaching materials using pictures, songs, or videos. These media-based materials have been broadly introduced into our language classrooms and promoted the traditional language learning to a holistic and multi-sensory level. Researchers have suggested that learning was facilitated when visual and audio representations co-occurred in a person's working memory. In order to meaningfully comprehend a text in a multimedia format, learners select relevant pictorial and linguistic information, organize the input into coherent visual and verbal mental representations, and construct referential connections between the two (Mayer, 1997; Mayer \& Moreno, 2002).

\subsection{Effects of Pictorial and Audio Aids on L2 Vocabulary Learning}

Empirical studies have confirmed the effects of visual and audio aids on L2 vocabulary learning, and shown how pictures and translations enhanced language learning. Kellogg and Howe (1971) for example, found that L2 words accompanied with images or actual objects related to their meanings were learned more efficiently than those without such additional information. Terrell (1986) proved that combining unknown words with visual aids and a direct translation could facilitate and enhance vocabulary learning. Moreover, Underwood (1989, p. 19) suggested that we "remember images better than words, hence we remember words better if they are strongly associated with images." These studies not only proved the strengths of using visual plus audio aids in leaning L2 vocabulary, but also manifested the capacity theory that could be explained as pictures and sounds bridging the gap of unconnected themes, saving spaces for learners' working memory and eventually speeding up the process of comprehension. For instance, Oxford and Crookall (1990) argued that the combination of pictures and texts accessed more parts of the brain, therefore led to greater depth of processing than when text was processed alone. To conclude, in order to process information effectively, previous evidence has suggested learners to be provided with multiple opportunities with various formats under different contexts (Linbarger, 2006).

\subsection{Video}

Video is one of the popular multimedia tools to be chosen in language classrooms because it not only helps to display the content, to deepen comprehension, but also to enhance lexical and grammatical learning. For example, Balatova (1994) claimed that using video in the foreign language classroom helped students perceive the story more consistently in the sense that difficult and easy passages form a pattern. In addition, she investigated the effects of viewing French video with subtitles on students' vocabulary learning, and found that students learned significantly more vocabulary when they viewed the audio-visual materials with subtitles. Moreover, Canning-Wilson (2000) stated that video provided "scenes" where utterances were backed up by an action or body language and therefore made learning easier. Overall, video provides learners a lively model to follow compared to fixed reading texts. It also helps to create a direct link between the target language and learning mind. Finally, it increases learners' awareness of the target cultural phenomenon associated with the target language.

However, we can not talk about the value of using video in language learning without first giving a definition of what we mean by video. First of all, video is generally defined as the selection and sequence of messages in an audio-visual context. It allows teachers to introduce any aspects of real life into language learning environment, and thereby contextualizes the learning process (Sherman, 2003). Video combines sounds, images, and sometimes texts, together with the socio-cultural information about human acts, traditions, living styles, and their thinking patterns. In the present study, video was used as a comprehensible tool to help a group of EFL learners to learn English vocabulary. Furthermore, according to its functions, video can be (1) instructional, where the video itself is specifically created for language learners, and (2) authentic, where the video is originally created for native speakers of the target language such as films, TV series, or commercials. In the present study, authentic video was used to provide more "natural" input and genuine communicative language, to increase learner motivation, and hopefully to facilitate the learning of the target vocabulary.

\subsection{Subtitles}

Subtitling is informative because it supplies the viewer with "three different channels of information- the pictorial information, original sound track, and translation of the texts" (d'Ydewalle \& Gielen, 1999, p. 259). 
Generally speaking, there are three combinations of audio and caption types. (1) Standard subtitle is a combination of L2 audio with L1 caption. (2) Bimodal or Intralingual subtitle is the combination of L2 audio plus L2 caption. (3) Reversed subtitle is a combination of L1 audio and L2 caption. When d'Ydewalle \& Gielen (1992) examined learners' eye-movement recording while watching video to learn vocabulary, they concluded that reading of subtitles was an automatic process taking place independently of familiarity with subtitling, knowledge of the foreign language, and the availability of a sound track. They also argued that participants were able to recognize surprisingly well the precise formulation of subtitles (Gielen, 1988), and could perform well on their vocabulary tests for using L1 \& L2 subtitles (d'Ydewalle Pavakanun, 1996).

To sum up, according to previous studies, video can be an effective tool in learning L2 vocabulary under different circumstances. First of all, the combination of visual and audio aids, where messages are clarified and language points are enhanced, provides more rooms for learners' working memory capacity, and leads to more successful retention of the new information. In addition, before adopting video into classrooms, teachers should first define the type of video they tend to use such as the functions of the video (instructional vs. authentic) or subtitles (L1 vs. L2 captions). Finally, one should never ignore the social cultural messages embedded in video that allow learners to experience the lively use of the target language.

Even though previous studies have shown the positive effects of using video in language classrooms, there is still a neglect of studies exploring the learning process from learners' perspectives. Thereby, the purpose of this study aims to describe how the video (TV dramas) is adopted to teach vocabulary to a group of EFL learners and how do learners perceive their learning process with TV dramas.

\title{
3. The Study
}

\subsection{The Context}

The study was carried out in an English language center affiliated with a large, national university in Northern Taiwan. Twenty-eight students were registered in a four-skill English course for twelve weeks. The class met once a week. Each class lasted for three hours. Three study sessions were conducted; each lasted for about ninety minutes.

\subsection{Participants}

The participants were all adult Taiwanese learners aged from twenty to forty-five years old. Most of them have gotten a bachelor's degree in Taiwan, but four of them were still students at universities. Fifteen of them were females and thirteen were males. Before being assigned to classes, all twenty-eight students took a placement test (based on reading) and were leveled as low-intermediate to intermediate level learners. In Taiwan, English education started from junior high schools (although this policy has changed from 2000), so it is assumed that all the participants had had at least eight to ten years of study in English when they participated in the study.

\subsection{TV Drama}

Three reasons were given to explain the researcher's choices of using American TV drama as video resource in this study. First of all, since TV drama was originally created for native speakers of English, the language would be more authentic and "natural". Secondly, in TV dramas, most of the dialogues or situations are based on characters' everyday life, so it might be easier for learners to watch and "guess" the content. Finally, it is assumed that within TV dramas, the content is more relaxed and fun to watch so that learners will not be bored. Three American TV dramas were chosen for the study- "How I met Your Mother", "The King of Queens", and "Reba" (See Table 1, 2; and 3).

\section{Table 1. How I Met Your Mother}

\author{
Name: How I Met Your Mother \\ Background: An AmericanTV drama premiered on CBS on September 19, 2005. The story \\ starts with the main character, Ted Mosby, in the year 2030 recounts to his son and daughter the \\ events that led to his meeting their mother... \\ Duration of the clip: 12 minutes \\ Storyline: Ted tried to show his "casual" personality to this girl- Robin who he liked. However, \\ because of his carefree attitude, Robin never took his word seriously, and Ted had to pretend $t$ \\ here was a party at his apartment every night just to wait for Robin to show up...
}


Table 2. The King of Queens

Name: The King of Queens

Background: An American drama ran for nine seasons from 1998 to 2007, on CBS. Doug, who makes a living as a delivery driver spends most of his time at his home with his wife Carrie, who works as a secretary for a law firm .The situation is complicated by Arthur, Carrie's father who lives in the basement of their apartment, a person who can be quite handful.

Duration of the clip: 12 minutes

Storyline: In the restaurant, Doug and Carrie met their couple friend-Lisa and "the guy" who just announced their wedding and enforced everyone to go to their wedding ceremony. Doug and Carrie disliked Lisa's personality of being a control freak and her high-pitched voice. While discussing to go or not to go to the wedding, they discovered another reason to dislike the annoying couple.

Table 3. Reba

\section{Name: Reba}

Background: Premiered on the WB in 2001, the show is set in the suburbs of Houston, Texas. Reba is a single mother with three kids whose ex-husband Brock has left her to marry Barbara Jean, who was once their helper. At the same time, her older daughter Cheyenne married to her baby's father, her high school classmates Van Montgomery...when the story gets more complicated, laughs never stop...

Duration of the clip: 13 minutes

Storyline: Cheyenne was going to re-marry to her husband Van on their anniversary. The show went on when the whole family talking about how to decorate a beautiful wedding that could please both the bride and the gloom.

\subsection{Class Procedure}

The study was carried out by the researcher during class sessions. Each session lasts for about ninety minutes and involved a series of activities:

\subsubsection{Previewing}

The researcher introduced the background of the drama and the clips.

\subsubsection{Watch for the First Time}

Students watched the clip with subtitles.

\subsubsection{Comprehension Check}

The researcher led a class discussion in order to check students' comprehension.

\subsubsection{Word List}

The researcher provided a word list of target vocabulary.

\subsubsection{Watch for the Second Time}

Students watched the clip again and circled the words the heard or saw. They were also encouraged to write down words that were not on the list.

\subsubsection{Explore the Words}

Students shared their word lists with their classmates and discussed words they learned from the clip.

\subsubsection{Class Discussion}

The researcher led the class to discuss the meaning of the words and how they were used in the drama.

\subsubsection{Watch for the Last Time}

Students watched the clip for the last time.

\subsubsection{Wrap-up}

The researcher wrapped up with a review of the target words. 


\subsection{Data Collection and Analysis}

The data was collected through five 4-likert scale questions followed by a detailed interview with each student. The interview was audio taped by the researcher and transcribed afterwards for data analysis.

\section{Result and Discussion}

This section shows each of the five questions and its results as well as students' interview answers.

\subsection{Found Watching TV Drama Pleasant}

Table 4. Result of questions 1

\begin{tabular}{lllll}
\hline & Agree & Slightly Agree & Slightly Disagree & Disagree \\
\hline Number of students & 26 & 2 & 0 & 0 \\
Percentage & $93 \%$ & $7 \%$ & & \\
\hline
\end{tabular}

As shown in Table 4, most of the students (26 students; $93 \%$ ) agreed that watching American drama was pleasant, and only a few of them slightly agree on the statement. In the interview, students also gave their comments on this question:

"Although I didn't understand at the first time, I found it funny and hilarious!"

"It's lively, vivid, and practical which makes me want to learn!"

It seems that most students could make sense the idea of implementing TV drama in a language classroom and they did enjoy watching it during the process. The result also supports the possibility of using TV drama to motivate students' learning of a language and making the learning process more fun and delightful.

\subsection{Watching TV Drama Helps Me Learn L2 Vocabulary}

Table 5. Results of questions 2

\begin{tabular}{lllll}
\hline & Agree & Slightly Agree & Slightly Disagree & Disagree \\
\hline Number of students & 18 & 8 & 2 & 0 \\
Percentage & $64 \%$ & $29 \%$ & $7 \%$ & \\
\hline
\end{tabular}

As shown in Table 5, more than $50 \%$ students agreed and slightly agreed that watching TV drama helped them learn L2 vocabulary; only $7 \%$ of them slightly disagreed. Some positive comments were:

"I like the subtitles because I can see the words, hear them, and at the same time watch the show."

"The process of learning is interesting, receiving, and useful for us."

"We can learn many idioms and colloquial words."

"I learned many interesting words that I have never seen in the textbook."

"Vision can turn into deep images. It helps me memorize word spelling."

The result showed that the students were aware of their own learning process of L2 vocabulary through watching TV drama. For example, they were able to point out that TV drama helped them to connect the word meaning with the storyline. Moreover, they thought that the subtitles and images provided a chance for vocabulary comprehension and retention. They also noticed that TV drama contained more colloquial and daily life vocabulary compared to written textbooks. Overall, students' feedback seems to echoes previous researchers' supports on the positive effects of watching television programs to learn L2 vocabulary (Pavakanun \& d'Ydewalle, 1992; d'Ydewalle \& Pavakanun, 1997; d'Ydewalle \& Van de Poel, 1999).

However, the students also appeared to be suspicious about the genuineness of the word usage in TV setting. When asked for more details, they said they were afraid that words learned from TV might not be high frequency words used by native speakers in everyday life. Some of them expressed their concerns:

"I am not sure if the language in TV drama is genuine because they are all scripted."

"I wonder if I can really use words I learned from TV in daily life."

Although these are just individual comments, they might reveal students' unfamiliarity of the target language or 
the context that the language is being spoken. Future studies should explore more about how this "hesitancy" might influence the learning process as well as students' performances.

\subsection{The Level of Vocabulary in TV Drama is Appropriate for Me}

Table 6. Results of questions 3

\begin{tabular}{lllll}
\hline & Agree & Slightly Agree & Slightly Disagree & Disagree \\
\hline Number of students & 13 & 7 & 5 & 3 \\
Percentage & $46 \%$ & $25 \%$ & $18 \%$ & $11 \%$ \\
\hline
\end{tabular}

According to Table 6 , more than half of the students agreed and slightly agreed that the level of vocabulary was appropriate for them. Still, nearly $30 \%$ of the students disagreed and slightly disagreed. Here shows students positive and negative comments:

"Some of the words are difficult to learn, but repetition seems to be really helpful. After watching them for a couple of times, I can understand the words."

"I think some of the phrases appeared several times in the clip. At first, I couldn't understand why Ted said the word casual, but I could guess the meaning after he used it many times."

"People in the show speak very fast; it's difficult for me to catch up."

"Sometimes the pronunciation was blurred!"

"There were too many new words; I didn't have time to write down everything. They speak too fast!"

The result could be explained by previous findings. To estimate the appropriate vocabulary level in a text, researchers usually examine vocabulary "coverage". For example, according to Laufer (1989), 95\% coverage of vocabulary is "required" for "adequate comprehension" of television programs. That means in order to understand a television program or an episode; students need to know $95 \%$ of the vocabulary in the text. Moreover, Nation (2006) proposed that $98 \%$ coverage of vocabulary is "ideal" for vocabulary comprehension of television programs. Then, Webb and Rodgers (2009) investigated the vocabulary demands of American television programs such as news, drama, science fiction, children's programs, older programs, and situation comedies and found that American drama reached 95\% coverage of 3,000 most frequent word families and 98\% coverage of 6,000 word families compared to American news' $95 \%$ coverage of 4,000 word families and $98 \%$ coverage of 8,000 word families and children's program's $95 \%$ coverage of 2,000 word families and $98 \%$ of 5,000 word families. According to their results, we might hypothesize that the vocabulary level of American drama seems to be higher than American children's programs and lower than American news. Therefore, it is possible that for some of the participants (who are low-intermediate level students), understanding the words in American drama could be troublesome for them. Just like one student has suggested in the interview: "next time, I hope the teacher can play cartoons, so that I can understand more", future researchers should consider the relationship between the word coverage in the text and learners' proficiency levels.

4.4 Compared to Reading Text, I Prefer Watching TV Drama to Learn Vocabulary

Table 7. Results of questions 4

\begin{tabular}{lllll}
\hline & Agree & Slightly Agree & Slightly Disagree & Disagree \\
\hline Number of students & 6 & 14 & 8 & 0 \\
Percentage & $21 \%$ & $50 \%$ & $29 \%$ & \\
\hline
\end{tabular}

Shown in Table 7, $50 \%$ of students slightly agreed that they would choose TV drama over written text while learning L2 vocabulary. Also, $21 \%$ students agreed and $29 \%$ students slightly disagreed. Their responses seem to support previous studies that comparing to text-only, picture-only, or text plus picture, video which is the combination of text, picture and audio was the most effective type of "annotation" to facilitate vocabulary learning (Al-Seghaver, 2001; Yeh \& Wang, 2003 ). The possible explanation is that the picture provides learners visual input so that they can imagine the "context" while the audio input helps to deepen the image by saying the words and lines out. Furthermore, the subtitles function to strengthen the memorization of the spelling and the letter combination (orthography) of the target words. 
However, interference still exists since learners need to process two channels (visual plus audio) simultaneously. Some concerns were listed:

"I felt anxious while watching the video, because I felt I didn't know every word!"

"It takes too much time to think and digest. If I want to focus on the vocabulary, I will lose track of the content. But if I focus on the content, I forget to look at the words."

It is possible that this interference could cause anxiety and therefore diminish the positive role of TV drama in learning L2 words. Although current study did not focus on the gains and loss of L2 words, the negative role of watching TV drama while learning L2 vocabulary could be a critical direction for further investigation.

\subsection{In the Future, I Will Recommend My Teacher Using TV Drama to Help Students Learn L2 Vocabulary}

Table 7. Results of questions 5

\begin{tabular}{lllll}
\hline & Agree & Slightly Agree & Slightly Disagree & Disagree \\
\hline Number of students & 20 & 7 & 1 & 0 \\
Percentage & $71 \%$ & $25 \%$ & $4 \%$ & \\
\hline
\end{tabular}

As shown in Table 7, most of the students agreed that they would recommend using TV drama to learn L2 vocabulary in the classroom; only one of them slightly disagreed. Some comments from the students:

"I think watching TV drama also improves my listening ability."

"Subtitles are very important for me, because I can listen to the pronunciation of the words. I knew some of the words before I watched the clips, but I didn't know they could be used in that situation."

"I love to learn new vocabulary from TV drama. It is fun, interesting, and I save some energy! I think every student would love this way of learning."

From the questionnaire and interview results, it is confident for us to say that most learners hold a positive attitude towards the benefits of using American TV drama to help L2 vocabulary learning. They see watching TV drama as a fun and enjoyable activity that also provides things worth learning. Moreover, they propose crucial comments that help the researcher to manifest the process of learning L2 vocabulary through TV drama and raise critical issues for further researchers from the learner's perspective. The following part will conclude the findings of the current study with theories and hypotheses in the filed of second language acquisition.

\section{Conclusion and Limitation}

\subsection{Limited Working Memory}

According to cognitive load theory (CLT), the working memory system is a place where information is temperately stored and processed in our brain and its space is limited. That means if learners can not use their limited working memory efficiently, it is very possible they encounter "forgetting" or "losing" things they just learn minutes ago.

In the present study, students not only supported the positive effects of using American TV drama to promote L2 vocabulary learning, they also illustrated the process of learning. For example, they found that video contained "images" that helped them to memorize words easily. According to students, the plots, the events, and the characters' emotions all helped them to learn the target words. Moreover, repetitions provided a chance for memory enhancement. For example, some of the words appeared more than once in the clip and drew learners' attention. After seeing and hearing the target words a couple of times, students said they became familiar with the definition and usage of the words. Also, the series of instructional activities served as an "organizer" that helped students to process information more efficiently. For instance, previewing and comprehension check gave students an overview of the context of the episode. By previewing and checking the word lists, they learned target words more systematically and effortlessly.

\subsection{Context Facilitates Learning}

According to Tomlin and Villa (1994), context facilitates second language acquisition when learners (1) discern elements of linguistic input from exposure; (2) perceive new or unusual characteristics in the event; and (3) establish a relationship between the linguistic input and the mental representation of the event. In this study, students reported that words were mostly noticed when they accompanied with the main characters' dramatic facial expressions and tones. Also, they claimed that they usually paid attention to words that "seemed" to make 
a big deal in the scene. On the other hands, they were afraid that they might miss some important messages if they failed to understand the meaning of some particular words. Finally, after comparing the values of learning vocabulary from TV drama and from traditional written texts, students were able to recognize that they learned more colloquial words and idioms such as on the fence, wing man, wacky, burp, awesome, limo, etc. from TV drama. These are also words that frequently used in everyday life but rarely appear in their textbooks.

In sum, from learners' perspectives, TV drama provides a "context" for them to perceive the linguistic features of the target words, to observe the authentic use of those words in specific situations, and to "hold" the meaning of the words in their memory system.

\subsection{Noticing, Learning, and Acquiring}

For a long time, linguists debated on the definitions of "learning" and "acquiring" a language as well as their relationship with "noticing". For example, according to Krashen (1981), learning is different from acquisition where the former involves "consciousness" and the later is an "unconscious" activity. However, Schmidt (1990) thinks that the level of "noticing" (consciousness) is necessary for both learning and acquisition. In the current study, students reported that they noticed the target words in various conditions such as when the words repeatedly occurred in the context or when the words were used with an unusual meaning. Moreover, they thought that their learning of the vocabulary had a lot to do with the researcher's instructions and classroom activities. It seems that both Krashen and Schmidt's theory can be proved here where "noticing", or learners' conscious awareness of the input, is essential for learning L2 vocabulary with American TV drama.

However, we can not certain that the learning of the L2 words from American TV drama equals to acquisition since the interview asked learners to "consciously" recall the process of learning. In addition, since the students from the current study were all low-intermediate to intermediate level learners, we might hypothesize that for beginner or advanced level learners, the result could be very different. Therefore, for further research, instrument that measures learners' acquisition of the target words and a bigger sample of learners at different levels should be considered and involved.

In conclusion, the result of this study responds to the cognitive load theory where pictures and sounds bridge the gap of unconnected themes, save spaces for learners' limited working memory and therefore speed up the process of learning. From learners' perspectives, watching American TV drama does help them to learn and comprehend the target vocabulary especially when the words appear more than once, in a dramatic way, or with an unexpected meaning. Finally, the result of this study is not in favor of incidental vocabulary learning since a series of class instructional activities were involved such as previewing, word listing, and discussion that were all claimed to be significant.

\section{References}

Akbulut, Y. (2007). Variables predicting foreign language reading comprehension and vocabulary acquisition in a linear hypermedia environment. The Turkish Online Journal of Educational Technology, 6(1), 53-60. Retrieved from http://www.tojet.net/volumes/v6i1.pdf

Al-Seghayer, K. (2001). The effect of multimedia annotation modes on L2 vocabulary acquisition: a comparative study. Language Learning \& Technology, 5(1), 202-232. Retrieved from http://lt.msu.edu/vol5num1/alseghayer/default.html

Altman, R. (1989). The video connection: Integrating video into language teaching. Boston: Houghton Mifflin.

Crossley, S. A., Louwerse, M. M., McCarthy, P. M., \& McNamara, D. S. (2007). A linguistic analysis of simplified and authentic texts. The Modern Language Journal, 91(1), 15-30. http://dx.doi.org/10.1111/j.1540-4781.2007.00507.x

Doughty, C. (1998). Acquiring competence in a second language: Form and function. In H. Byrnes (Ed.), Learning foreign and second languages (pp. 128-156). New York: Modern Language Association.

d'Ydewalle, G., \& Gielen, I. (1992). Attention allocation with overlapping sound, image, and text. In K, Rayner (Ed,), Eye movement and visual cognition: Scene perception and reading (pp. 415-427). New York: Springer.

d'Ydewalle, G., \& Pavakanun, U. (1995). Acquisition of a second/foreign language by viewing a television program. In P. Winterhoff-Spurk (Ed.), Psychology of media in Europe: The state of the art-perspectives for the future (pp. 51-64). Opladen: Westdeutscher Verlag.

d'Ydewalle, G., \& Van de Poel, M. (1999). Incidental Foreign-Language Acquisition by Children Watching Subtitled Television Programs. Journal of Psycholinguistic Research, 28(3), 227-244. 
http://dx.doi.org/10.1023/A:1023202130625

Herron, C. A., Hanley, J. E. B., \& Cole, S. P. (1995). A comparison study of two advance organizers for introducing beginning foreign language students to video. Modern Language Journal, 79(3), 387-395. http://dx.doi.org/10.1111/j.1540-4781.1995.tb01116.x

Hoogeveen, M. J. (1995). Towards a new multimedia paradigm: is multimedia assisted instruction really effective? ED-MEDIA 95 Proceedings, June, Graz, Austria.

Krashen, S. D. (1981). Second Language Acquisition and Second Language Learning. Oxford: Pergamon Press.

Koskinen, P. S., Wilson, R. M., Gambrell, L. B., \& Neuman, S. B. (1993). Captioned video and vocabulary learning: an innovative practice in literacy instruction. The Reading Teacher, 47(1), 36-43.

Laufer, B. (1989). What percentage of text lexis is essential for comprehension? In C. Lauren, \& M. Nordman (Eds.), Special language: From humans thinking to thinking machines (pp. 316-323). Clevedon, UK: Multilingual Matters.

Mayer, R. E. (1997). Multimedia learning: Are we asking the right questions? Educational Psychologist, 32(1), 1-19. http://dx.doi.org/10.1207/s15326985ep3201_1

Mayer, R. E., \& Moreno, R. (2002). Aids to computer-based multimedia learning. Learning and Instruction, 12, 107-110. http://dx.doi.org/10.1016/S0959-4752(01)00018-4

Nation, I. S. P. (2006). How large a vocabulary is needed for reading and listening. The Canadian Modern Language Review, 63(1), 59-82. http://dx.doi.org/10.3138/cmlr.63.1.59

Neuman, S., Burden, D., \& Holden, E. (1990). Enhancing children's comprehension of a televised story through previewing. Journal of Educational Research, 83, 258-265.

Pavakanun, U., \& d'Ydewalle, G. (1992). Watching foreign television programs and language learning. In F. L. Engel, D. G. Bouwhuis, T. Bösser, \& G. d'Ydewalle (Eds.), Cognitive modeling and interactive environments in language learning (pp. 193-8). Berlin: Springer.

Schmidt, R. W. (1990). The role of consciousness in second language learning. Applied Linguistics, 11, 129-158. http://dx.doi.org/10.1093/applin/11.2.129

Secules, T., Herron, C., \& Tomasello, M. (1992). The effect of video context on foreign language learning. Modern Language Journal, 76(4), 480-490. http://dx.doi.org/10.2307/330049

Shekary, M., \& Tahririan, M. H. (2006). Negotiation of meaning and noticing in text-based online chat. Modern Language Journal, 90(4), 557-573. http://dx.doi.org/10.1111/j.1540-4781.2006.00504.x

Snyder, H., \& Colon, I. (1988). Foreign language acquisition and audio-visual aids. Foreign Language Annals, 21(4), 343-384. http://dx.doi.org/10.1111/j.1944-9720.1988.tb01079.x

Stevens, V. (1989). A direction for CALL: From behaviorist to humanistic courseware. In M. Pennington (Ed.), Teaching languages with computers: The state of the art. La Jolla, CA: Athelstan.

Tomlin, R., \& Villa, V. (1994). Attention in cognitive science and second language acquisition. Studies in Second Language Acquisition, 16, 183-203. http://dx.doi.org/10.1017/S0272263100012870

Underwood, J. (1989). HyperCard and interactive video. CALICO Journal. 6(3), 7-20.

Underwood, J. (1990). Research in hypertext: Desiderata. Computer Assisted English Language Learning Journal, 1(4), 33-36.

Webb, S., \& Rodgers, M. P. H. (2009). Vocabulary demands of television programs. Language Learning, 59(2), 335-366. http://dx.doi.org/10.1111/j.1467-9922.2009.00509.x

Yeh, Y., \& Wang, C. (2003). Effects of multimedia vocabulary annotations and learning styles on vocabulary learning. CALICO Journal, 21(1), 131-144. 